\title{
The Application of PRIMET For Pesticide Registration and Monitoring in Ethiopia
}

Berhan Teklu ( $\sim$ birhanme@gmail.com )

Istanbul Technical University: Istanbul Teknik Universitesi https://orcid.org/0000-0001-8228-1560

Sevil Deniz Yakan

Istanbul Technical University - Ayazaga Campus: Istanbul Teknik Universitesi

\section{Research Article}

Keywords: PRIMET, risk assessment, protection goals, pesticides

Posted Date: April 27th, 2021

DOI: https://doi.org/10.21203/rs.3.rs-425656/v1

License: () (7) This work is licensed under a Creative Commons Attribution 4.0 International License. Read Full License 


\section{Abstract}

Pesticide registration is an activity often not supported with proper risk assessment procedures in developing countries like Ethiopia. In this study, we tried the PRIMET (Pesticide Risks in the Tropics for Man, Environment and Trade), a tool developed to assess the risks to non-target protection goals believed to assist the pesticide registration and monitoring activities in Ethiopia. For this study, seven pesticides (imdacloprid, difenoconazole, metalaxyl, dimethoate, thiamethoxam, nicosulfuron and bupirimate) were selected randomly and their data of physico-chemical characteristics, toxicological information and pesticide use were mined from either the information given on the dossier or PPDB (Pesticides Properties Database). Results indicated that imidacloprid, dimethoate and thiamethoxam are highly risky to bees when bee hives are present inside the field of the sprayed crop, while Thiamethoxam is highly risky at when hives are present in and off field crop situation. Another outcome was that imidacloprid and dimethoate are expected to have high acute risk for birds, while difenoconazole, metalaxyl, dimethoate showed high acute and chronic risks to the aquatic ecosystem, respectively. Future studies should give emphasis on how the results of risk assessment can be practical to help the registration processes and how the results are compared with actual measurement values.

\section{Introduction}

Global occurrence of acute pesticide poisoning is estimated to be around three million every year, making it a worldwide public health problem (Damalas and Koutroubas 2016; Yáñez et al. 2002). The pesticide poisoning and related environmental problems in developing countries are more frequent, considering the high trade rate of pesticides in response to the boom in agricultural activities and the associated high prevalence of inappropriate handling, distribution and use (Mengistie et al. 2016; Mormeta et al. 2019). The main reason for this fact is lack of effective and functional regulatory bodies with appropriate policies, rules and regulations together with pesticide risk quantification and management systems, that support the pesticide registration and control mechanisms (Mengistie et al. 2016; Negatu et al. 2016). The safe use of the pesticides is ensured by performing registration and post-registration monitoring of the pesticides via considerations of the administrative, scientific and laboratory evaluations of the active ingredients and the formulated products of the pesticides (Handford et al. 2015).

The main objective of making registration and post-registration surveillance of a pesticide is minimizing the unacceptable risks to human or environment, by pre-determining the risk through risk assessment and determining the actual situation on the ground from the post registration surveillance results, as applied products are toxic to many non-target organisms in the nature (Fargnoli et al. 2019; Beketov et al. 2013; Hallmann et al. 2014). Many countries adopt modelbased risk assessment as a method for evaluating the impacts of the pesticides to non-target organisms. The experience of EU (European Union) is the one which worth to be mentioned and taken as an example to many pesticide regulatory bodies around the world, keeping in mind that the model-based risk assessment has its own limitations and strengths. Thus, this method is widely applied to assess the fate and the effects of the pesticides for the registration purposes in Europe (Schäfer et al. 2019; FOCUS, 2001).

In general, it is believed that the PRIMET_Registration_Ethiopia_1.1 model, which was developed for the integrated fate, effects, and risk assessment, took the current registration system in Ethiopia and in the continent of Africa one step forward. Unlike other similar trials by an older version of PRIMET that only focus on simple risk assessment purposes (Ansara Ross et al. 2010 and Malherbe et al. 2013), PRIMET_Registration_Ethiopia_1.1 is a tool capable of risk assessment for a decision making of pesticide registration, so that it helps both in registration and monitoring purposes. This tool is developed and modified to consider specific scenarios in Ethiopia and can be taken as a pioneer among other countries with similar geographical characteristics (Wipfler et al. 2014).

This study focused on to make a trial risk assessment using PRIMET model on registered pesticides in Ethiopia. Results are believed to show the applicability and appropriateness of the tools like PRIMET for the registration and post-registration purposes in developing countries like Ethiopia. Therefore, the objectives of present study are to evaluate randomly selected active ingredients of the pesticides registered in Ethiopia using PRIMET and to investigate the applicability of the model-based risk assessment for the registration of pesticides in developing countries like Ethiopia, as an example for other countries with similar geographical characteristics.

\section{Methods}

\subsection{General approach}

Seven randomly selected active ingredients of registered pesticides were evaluated for their risks to the environment and drinking water. The needed data were obtained from either the supplementary information from the attached documentation as dossier, the PPDB (Pesticides Properties DataBase) or Ecotox (Ecotoxicology Database). Risks were quantified and the status of the pesticide was indicated by using PRIMET for the registration process. The risks were determined for the endpoints identified in PRIMET (i.e. for human/animal risks using surface water as a source of drinking water, and for chronic and acute environmental risks in the aquatic ecosystem, chronic and acute risks in the terrestrial ecosystem, in-crop and off-crop exposures for bees). Results were analysed based on the risk assessment outputs of PRIMET to help about the decisions concerning registration status. Basic recommendations were put forward and some major concerns, questions or misconceptions were also discussed.

\subsection{Data mining and processing}

Seven randomly selected active ingredients of registered pesticides were evaluated to determine the risks for environment, man and other non-target organisms. The names of the agents or the registrants in Ethiopia are not listed for the reason of confidentiality. All pesticides are registered and currently under use in Ethiopia. The overall toxicological, physico-chemical and pesticide use data needed to run this tool was accessed from the dossier submitted by the applicant or other data sources like PPDB. The risk assessment can be referred as first tier as it can easily be evaluated by using basic and readily accessible data. Final output is designed to give some indicative risk categories for non-target organisms like bees and birds, soil dwelling organisms (e.g. 
earth worms), including risks in association with drinking surface or ground water in the rural Ethiopian setting. The overall process of risk determination is expressed in Fig. 1.

The three scenario locations listed in PRIMET i.e. 1, 2a and $2 b$ are considered valid for the risk classification of aquatic ecosystems in the present study. Protection goals were set to be humans/animals using surface water as a source of drinking water and aquatic organisms living in surface water after a discussion and following recommendations in workshops with experts from the Animal and Plant Health Regulatory Directorate, Addis Ababa University Institute of Biodiversity and the Ethiopian Agricultural Research Institute. A representative scenario location was selected after the consideration of the protection goal within the candidate grid. In detail, the main criteria for the selection of the representative scenario were the presence of crops with high use of pesticides and consideration of being well populated (Teklu et al. 2014).

The features of the representative scenario location 1 are the availability of areas with small streams, elevation above $1500 \mathrm{~m}$ with annual rain fall of $>20 \mathrm{~mm}$ for at least 46 days per annum with long term average annual precipitation around $2581 \mathrm{~mm}$. Scenario location 2a represents the areas with temporary ponds below $1500 \mathrm{~m}$ and with more than $500 \mathrm{~mm}$ of rain per annum, with annual rain fall of $>20 \mathrm{~mm}$ for at least 46 days per annum, with long term average annual

precipitation around $1702 \mathrm{~mm}$. Scenario location $2 \mathrm{~b}$ represents the areas with temporary ponds between $1500 \mathrm{~m}$ and $2000 \mathrm{~m}$ elevation, with annual rain fall of $>20 \mathrm{~mm}$ for at least 21 days per annum, with long term average annual precipitation around $2779 \mathrm{~mm}$. Details of the scenario locations and how they are developed can be found at Adriaanse et al. (2015). Thus, risks calculated in these study areas are expected to vary for each scenario locations and in the present study, the highest risk is taken as a representative of the three worst case scenarios. Moreover, Risks for Birds, Bees and Terrestrial Ecosystems are determined as default without taking scenario locations into considerations (Wipfler et al. 2014).

\section{Result And Discussion}

\subsection{Pesticide use and type}

Pesticide type with their usage frequency and interval are important factors that determine the PEC (Predicted Environmental Concentrations) values in environmental compartments; the risk associated with a specific active ingredient (a.i.) released to the environment depends on the toxicity of that particular a.i. as risk is expressed as the ratio of what is exposed to how much toxic the pollutant is (Teklu et al. 2014). The required physico-chemical data are given in Table 1, while the toxicity data are given in Table 2 and the application scheme figures are given in Table 3.

Table 1

Physico-chemical properties of the randomly selected pesticides from active dossier

\begin{tabular}{|c|c|c|c|c|c|c|c|c|c|}
\hline$\#^{*}$ & $\begin{array}{l}\text { Active ingredient } \\
\text { (a.i.) }\end{array}$ & $\begin{array}{l}\mathrm{DT}_{50} \\
\text { water } \\
\text { (d) }\end{array}$ & $\begin{array}{l}\mathrm{DT}_{50} \\
\text { sediment (d) }\end{array}$ & $\begin{array}{l}\mathrm{DT}_{50} \text { soil } \\
\text { (d) }\end{array}$ & $\star \star M_{\text {pesticide }}$ & $\begin{array}{l}\text { Solubility }\left(T_{\text {ref }}\right) \\
\left(\mathrm{mg} \mathrm{L}^{-1}\right)\end{array}$ & $\begin{array}{l}\text { Vapor pressure at } \\
25^{\circ} \mathrm{C}(\mathrm{mPa})\end{array}$ & $\begin{array}{l}\mathrm{K}_{\mathrm{oc}} \\
\text { soil }\end{array}$ & $\begin{array}{l}\text { Pesticide } \\
\text { category* }\end{array}$ \\
\hline $\mathrm{P} 1$ & Imidacloprid & 30 & 129 & 180 & 255.66 & 610 & $4.00 \mathrm{E}-7$ & 225 & IN \\
\hline P2 & Difenoconazole & 3 & 1053 & 130 & 406.26 & 15 & 3.33E-05 & 3760 & FU \\
\hline P3 & Metalaxyl & 56 & 56 & 36 & 279.33 & 8400 & 0.75 & 162 & FU \\
\hline P4 & Dimethoate & 45.3 & 15.2 & 2.6 & 52 & 39.8 & 0.25 & 28.3 & IN \\
\hline P5 & Thiamethoxam & 30.6 & 40 & 50 & 139.1 & 4100 & $6.60 \mathrm{E}-06$ & 56.2 & IN \\
\hline P6 & Nicosulfuron & 65 & 41.5 & 26 & 145 & 7500 & 8.00E-08 & 30 & $\mathrm{HE}$ \\
\hline P7 & Bupirimate & 6.2 & 42.5 & 79 & 46.9 & 13.06 & 0.057 & 1882 & FU \\
\hline
\end{tabular}

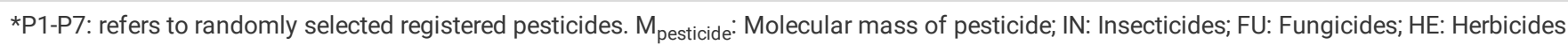

Note: Names of registrants/agents is not mentioned for confidentiality reason 
Table 2

Toxicity data as given in dossier or mined from either PPDB and dossier

\begin{tabular}{|c|c|c|c|c|c|c|c|c|c|c|c|c|}
\hline$\#$ & $\begin{array}{l}\text { Active } \\
\text { ingredient (a.i.) }\end{array}$ & $\begin{array}{l}{ }^{*} \mathrm{LC}_{50} \\
\text { bees } \\
\text { (ug } \\
\text { bees }^{-} \\
{ }^{1} \text { ) }\end{array}$ & $\begin{array}{l}\mathrm{LC}_{50} \\
\text { birds } \\
(\mathrm{mg} \\
\left.\mathrm{kg}^{-1}\right)\end{array}$ & $\begin{array}{l}\text { NOEC } \\
\text { birds } \\
\text { (mg } \\
\mathrm{kqbw}^{-} \\
{ }^{1} \text { day }^{-} \\
{ }^{1} \text { ) }\end{array}$ & $\begin{array}{l}\mathrm{LC}_{50} \\
\text { earth } \\
\text { worms } \\
(\mathrm{mg} \\
\left.\mathrm{kg}^{-1}\right)\end{array}$ & $\begin{array}{l}\text { NOECearthworms } \\
\left(\mathrm{mg} \mathrm{kg}^{-1}\right)\end{array}$ & $\begin{array}{l}\mathrm{EC}_{50} \\
\text { algae } \\
(\mathrm{mg} \\
\left.\mathrm{L}^{-1}\right)\end{array}$ & $\begin{array}{l}\mathrm{EC}_{50} \\
\text { macrophytes }\end{array}$ & $\begin{array}{l}\mathrm{L}(\mathrm{E}) \mathrm{C}_{50} \\
\text { fish } \\
(\mathrm{mg} \\
\left.\mathrm{kg}^{-1}\right)\end{array}$ & $\begin{array}{l}\text { NOECfish } \\
\left(\mathrm{mg} \mathrm{L}^{-1}\right)\end{array}$ & $\begin{array}{l}\mathrm{L}(\mathrm{E}) \mathrm{C}_{50} \\
\text { invertebrates } \\
\left(\mathrm{mg} \mathrm{L}^{-1}\right)\end{array}$ & $\begin{array}{l}\text { NOE } \\
(\mathrm{mg}\end{array}$ \\
\hline P1 & Imidacloprid & 0.081 & 31 & 0 & 10.7 & 0.178 & 10 & 100 & 10 & 9.02 & 85 & 1.8 \\
\hline P2 & Difenoconazole & 100 & 2150 & & 6110 & - & 0.032 & - & 1.1 & 0.023 & 0.77 & $0.0 \mathrm{C}$ \\
\hline P3 & Metalaxyl & 200 & 1466 & 10000 & 1000 & - & 0.42 & 85 & 0.96 & - & 3.47 & - \\
\hline P4 & Dimethoate & 0.15 & 10.5 & 14.8 & 31 & 2.87 & 90.4 & & 30.2 & 0.4 & 2 & 0.04 \\
\hline P5 & Thiamethoxam & 0.024 & 576 & 2503 & 1000 & 5.34 & 100 & 90 & 125 & 20 & 100 & 100 \\
\hline P6 & Nicosulfuron & 76 & 2000 & 1603 & 1000 & - & 7.8 & 0.002 & 65.7 & 10 & 90 & 5.2 \\
\hline P7 & Bupirimate & 50 & 10000 & 2091 & 500 & - & 1.6 & - & 1 & 0.3 & 3.41 & 0.56 \\
\hline
\end{tabular}

AfRD : Acute Reference Dose; ADI : Acceptable Daily Intake; - no data available.

**All values for $\mathrm{LC}_{50}$ bees are taken as the contact acute duration of $48 \mathrm{hr}$. NOEC values for bees are not available due to the acute risk estimation method of under the circumstances of in-crop and off crop, in addition to the fact that worker bees have a short life span like 2-5 weeks of time period.

Note: In most cases data mined or compared with PPDB for the reliability reasons.

Table 3

Application scheme data mined from efficacy study provided in the dossier

\begin{tabular}{|lllllll|}
\hline \# & $\begin{array}{l}\text { Active ingredient } \\
\text { (a.i.) }\end{array}$ & $\begin{array}{l}\text { Pesticide } \\
\text { category }\end{array}$ & $\begin{array}{l}\text { Application rate (kg/L. } \\
\text { ai/ha) }\end{array}$ & $\begin{array}{l}\text { Time } \\
\text { interval (d) }\end{array}$ & $\begin{array}{l}\text { Number of } \\
\text { applications }\end{array}$ & $\begin{array}{l}\text { Crops } \\
\text { registered for }\end{array}$ \\
\hline P1 & Imidacloprid & IN & 0.15 & 15 & 5 & Cabbage \\
\hline P2 & Difenoconazole & FU & 0.5 & 15 & 7 & Cabbage \\
\hline P3 & Metalaxyl & FU & 2.75 & 7 & 5 & Cabbage \\
\hline P4 & Dimethoate & IN & 0.75 & 15 & 3 & Onion \\
\hline P5 & Thiamethoxam & IN & 0.3 & 15 & 2 & Cotton \\
\hline P6 & Nicosulfuron & HB & 0.08 & 0 & 1 & Maize \\
\hline P7 & Bupirimate & FU & 0.0048 & 10 & 3 & Faba bean \\
\hline
\end{tabular}

Of the selected seven active ingredients, three of them are insecticides, three of them are fungicides and one of them is a herbicide. Except the fungicide metalaxy/ which is registered only in few EU countries, all selected pesticides are found to be registered in almost all EU countries. This result is encouraging in a way as all pesticides are being known and registered in countries which have advanced regulatory and registration systems. The fungicide difenoconazole is with the highest recommended frequency of application (7) followed by metalaxy/ and imidacloprid (5). Selected pesticides are registered for cabbage, maize, onion, cotton and fababean (Table 3).

\subsection{Risk assessment results}

Risk assessment (RA) of the pesticides before registration is an approach under-action in many regulatory bodies around the world, especially in the EU countries (Forbes et al. 2009; Galic et al. 2010). Model based risk assessment of plant protection products before registration helps the evaluation process before allowing it to be applied. Thus, this step allows better protection of human, environment and non-target organisms if outputs of RA results are properly applied (Brock et al. 2011). The results in this study indicated that Difenoconazole, Metalaxy/ and dimethoate present are with either high or possible acute and chronic risks to the aquatic ecosystem (Table 4). Pesticides like imidacloprid, dimethoate and thiamethoxam indicted high level of risk when bee hives are present within the crop field (in-crop) to bees while thiamethoxam were with high level of risk at both in and off crop situations. Birds are also under high acute risk when imidacloprid and dimethoate are applied. The terrestrial ecosystem is also under high chronic risk due to imidacloprid (Table 5). Generally, five of the examined pesticides pose either high or possible risks to one or more protection goals except nicosulfuron and bupirimate, which pose no risk or show negligible risk for all the examined protection goals. All the evaluated pesticides are found to pose no or negligible risks to humans using surface water as a source of drinking water. This result is in line with the former study results of Teklu et al. (2014) (Table 4).

\subsection{Decision making and policy implications}

Results of this study indicated that evaluating dossier data using PRIMET is applicable and helps the decision making process of the pesticide registration in Ethiopia (Fig. 2). Pesticide registration procedures in developing countries are very backward, missing all the scientific elements to evaluate the impact of pesticides on environment and human health (Wesseling et al. 2005). Most regulatory bodies are devoid of the desired skilled manpower to evaluate risks (Mengistie et al. 2016; Ecobichon 2001). Risk assessment is a major step for decision making of a pesticide registration in developed nations like EU. The use of toxicity data done in temperate area to represent species in tropical area is among the concerns raised but proofed to be possible by works like Teklu et al. (2016C) and Rico et al. (2010). Comparison of the PEC and actual measurement values are indicated on Teklu et al. (2016 A and B) indicating promising 
results although further similar large scale investigations are needed. This method is very helpful in the registration process in such a way that it guides the registrant on the overall impacts of the active ingredient to be released to the environment despite all its limitations (Forbes et al. 2009; Galic et al. 2010;

Dohmen et al. 2015; De Laender et al. 2014).

Tools like PRIMET are used to indicate the status of a.i.s to be registered making risk assessment for all the endpoints considered to be protected. Thus, the registration and the environmental monitoring programs in developing countries can be pushed one-step forward (Teklu et al. $2016 \mathrm{~A}$ and B, Teklu et al. 2015).

It is clearly stated in the Pesticide Registration and Control Proclamation 674/2010 of Ethiopia Article 5: 1(c) and (d) that no pesticide shall be registered if it is believed to be posing serious risk to human, animals and non-target species. Making risk assessment prior to the registration helps to inform the registrant about the risk status of the pesticide that is about to be registered and be mass distributed; so that, farmers will be informed about risks associated with the pesticide. Some requirements are also clearly indicated on the same proclamation Article 5: 2 (c) which states that registrants/pesticide applicators need to notify bee keepers or neighboring areas before application if a pesticide is found to be risky to bees. Thus, informing registrants about the risk category of the pesticide that they are about to register is crucial in terms of the healthy status of bees and other non-target organisms.

\section{Conclusion And Recommendation}

Results of the present study indicated that among of all the investigated seven pesticides registered in Ethiopia, nicosulfuron and bupirimate have low risks in terms of the proposed protection goals including the risks to humans, aquatic ecosystems, birds, bees and terrestrial ecosystems. Thus, it is important to evaluate the performance and actual impacts of these pesticides (imidacloprid, difenoconazole, metalaxyl, dimethoate, thiamethoxam) so that a clear picture of the risks associated with the particular non-target organism can be indicated. Furthermore, re-evaluating the registration, advising and making farmers aware on the risks associated with these pesticides are also important.

Despite the challenges of easy implementation of the use of PRIMET tool, due to the lack of awareness and highly trained experts in the area; it can be used effectively to support the pesticide registration system in Ethiopia. It is also good to consider the model as a guide to help the overall environmental monitoring program associated with pesticides, as the Predicted Environmental Concentrations can be compared with the real data. Only few trials have been attempted so far in the country in such regard. Working in this area is believed to increase the applicability and validity of the model and gives clues for future improvements. Applicability of this model also pave the way for other developing countries to go ahead one step forward in the current registration and monitoring systems of pesticides in terms of developing similar tools of risk assessment.

\section{Declarations}

\section{Data availability statement:}

All data generated or analysed during this study are included in this published article (and its supplementary information files).

\section{Conflict of interests:}

The authors declare no financial, commercial and legal conflict of interest directly or indirectly related to this published article.

\section{Ethics committee approval:}

The authors declare that this study does not need any ethics committee approval.

\section{Authors' contribution:}

Both authors contributed to the study conception and design. Material preparation, data collection and analysis were performed by Dr. Berhan M. Teklu and Dr. Sevil Deniz Yakan. The first draft of the manuscript was written by Dr. Berhan M. Teklu and Dr. Sevil Deniz Yakan commented on previous versions of the manuscript. Both authors read and approved the final manuscript.

\section{Funding:}

This study has been performed in the context of the post-doctoral project titled 'Mapping of aquatic ecological pollutants and risk assessment at the central rift valley of Ethiopia' which is funded by Istanbul Technical University Scientific Research Projects Unit (ITU - BAP Project Code: MAB-2020-42229).

\section{References}

1. Adriaanse P.I, TerHorst M.M.S., Teklu B.M., Deneer J.W., Woldeamanue L.A., Boesten J.J.T.I. (2015). Development of scenarios for drinking water produced from groundwater and surface water for use in the pesticide registration procedure of Ethiopia. Alterra Report 2674 , Wageningen, p 309.

2. Ansara-Ross T.M, Wepener V., van den Brink P.J., Ross M.J. (2008). Probabilistic risk assessment of the environmental impacts of pesticides in the Crocodile (west) Marico catchment, North-West Province. Water SA, 34: 637 - 644.

3. Beketov M.A., Kefford B.J., Schäfer R.B., Liess M. (2013). Pesticides reduce regional biodiversity of stream invertebrates. Proc Natl Acad Sci USA, 110:11039-11043. https ://doi.org/10.1073/pnas.13056 18110.

4. Brock T.C.M., Art G.H.P., ten Hulscher T.E.M., de Jong F.M.W., Luttik R., Roex E.W.M., Smit C.E. and van Vliet, P.J.M. (2011). Aquatic effect assessment for plant protection products. Alterra Report 2235, Alterra, part of Wageningen UR.. 
5. Damalas C.A., and Koutroubas S.D. (2016). Farmers' Exposure to Pesticides: Toxicity Types and Ways of Prevention. Toxics , 4, 1; doi:10.3390/toxics4010001.

6. De Laender F., van den Brink P.J., Colin R.J. and Antonio D.G. (2014). The ChimERA project: coupling mechanistic exposure and effect models into an integrated platform for ecological risk assessment. Environ Sci Pollut Res. DOI 10.1007/s11356-014-2605-5.

7. Dohmen G.P., Preuss T.G., Hamer M., Galic N., Strauss T., van den Brink P.J., De Laender F., and Bopp S. (2015). Population-Level Effects and Recovery of Aquatic Invertebrates after Multiple Applications of an Insecticide. Integr Environ Assess Manag, 9999: 1-15.

8. Ecobichon D.J. (2001). Pesticide use in developing countries. Toxicology 160: Issue, 1-3: (27-33).

9. Fargnoli M., Lombardi M., Puri D., Casorri L., Masciarelli E., Mandi'c-Raj cevi'c S., and Colosio C. (2019). The Safe Use of Pesticides: A Risk Assessment Procedure for the Enhancement of Occupational Health and Safety (OHS) Management. Int. J. Environ. Res. Public Health, 16, 310; doi:10.3390/ijerph16030310.

10. FOCUS (2001). FOCUS surface water scenarios in the EU evaluation process under 91/414/EEC. Report of the FOCUS Surface Water Scenarios Workgroup, EC. Document Reference SANCO/4802/2001-rev2., European Commission, Brussels Belgium.

11. Forbes V.E., Hommen U., Thorbek P., Heimbach F., van den Brink P.J., Wogram J., Thulke H.H., Grimm V. (2009). Ecological models in support of regulatory risk assessments of pesticides: Developing a strategy for the future. Integr EnvironAssess Manag, 5:167-172.

12. Galic N., Hommen U., Baveco J.M., van den Brink P.J. (2010). Potential application of population models in the European ecological risk assessment of chemicals II: Review of models and their potential to address environmental protection aims. Integr Environ Assess Manag, 6:338-360.

13. Hallmann C.A., Foppen R.P.B., van Turnhout C.A.M. et. al. (2014). Declines in insectivorous birds are associated with high neonicotinoid concentrations. Nature, 511:341-343. https ://doi.org/10.1038/natur e13531.

14. Handford C.E., Elliott C.T.,and Campbell K. (2015). A review of the global pesticide legislation and the scale of challenge in reaching the global harmonization of food safety standards. Integr Environ Assess Manag, 11(4):525-36. doi: 10.1002/ieam.1635.

15. Malherbe W., Van Vuren J.H.J., Wepener V. (2013). Preliminary risk assessment of common-use pesticides using PRIMET and PERPEST pesticide risk models in a semi-arid subtropical region. Water Sa, 39(5): 599-610.

16. Mengistie B.T., Mol A.P.J., Oosterveer P. (2016). Pesticide use practices in the central rift valley of Ethiopia. Environ. Dev. Sustain, http://dx.doi.org/10.1007/s10668-015-9728-9.

17. Mormeta B.N. (2019). Assessment of pesticide hazard related knowledge and practices of agricultural extension workers in selected small-scale horticulture production areas in Ethiopia. J Environ Agri and Int Devl- JAEID, 113 (1): 5-15 DOI: 10.12895/jaeid.20191.739.

18. Negatu B., Kromhout H., Mekonnen Y., Vermeulen R. (2016). Use of Chemical Pesticides in Ethiopia: A Cross-Sectional Comparative Study on Knowledge, Attitude and Practice of Farmers and Farm Workers in Three Farming Systems. Ann. Occup. Hyg, 60(5), 551-566.

19. Rico A., Geber-Correa R., Campos P., Garcia M., Waichman A., Van den Brink P.J. (2010). Effect of parathion-methyl on Amazonian fish and freshwater invertebrates: a comparison of sensitivity with temperate data. Arch Environ Contam Toxicol, 58:765-771.

20. Schäfer R.B., Liess M., Altenburger R., Filser J., Hollert H., Ros-Nickoll M., Schäffer A., Scheringer, M. (2019). Future pesticide risk assessment narrowing the gap between intention and reality. Environ Sci Eur. 31:21. https://doi.org/10.1186/s12302-019-0203-3

21. Teklu B.M., Adriaanse P.I., Ter Horst M.M.S., Deneer J.W., van den Brink P.J. (2014). Surface water risk assessment of pesticides in Ethiopia. Sci Total Environ, 508:566-574.

22. Teklu B.M., Hailu A., Wiegant D.A., Scholten B.S., van den Brink P.J., (2016A). Impacts of nutrients and pesticides from small and large scale horticulture on the water quality and ecology of the Lake Ziway catchment, Ethiopia. Env. Sci.Pollut. Res., http://dx.doi.org/10.1007/s11356-016-6714-1.

23. Teklu B.M., Adriaanse P.I., van den Brink P.J. (2016B). Monitoring and risk assessment of pesticides in the irrigations systems in Debre Zeit, Ethiopia. Chemosphere, 161. 280-291.

24. Teklu B.M., Retta N; van den Brink P.J, (2016C). Sensitivity of Ethiopian aquatic macroinvertebrates to the pesticides endosulfan and diazinon, compared to literature data. Ecotoxicology, 25:1226-1233.

25. Wesseling C., Corriols M., Bravo, V. (2005) Acute pesticide poisoning and pesticide registration in Central America. Toxicol Appl Pharmacol, 207(2):697705.

26. Wipfler E.L., Adriaanse P.I., ter Horst M.M.S., Vlaming J., van den Brink P.J., Peeters F.M., Deneer J.W., Boesten J.J.T.I., Groenwold J.G. (2014). PRIMET_ Registration_Ethiopia_1.1, technical description and manual. In: A Decision Support System for Assessing Pesticide Risk in the Tropics to Man, Environment and Trade, for Pesticide Registration in Ethiopia. Altera report 2573, Wageningen, The Netherlands.

\section{Tables}

Due to technical limitations, table 4,5 is only available as a download in the Supplemental Files section.

\section{Figures}


- Pesticdes are selected randomly from shelf dossiers

-All pesticides are registered and currently under the Ethiopian pesticide registration list

\section{Data mining and deciding}

\section{scenario}

- Toxicological and physico-

chemical data mined from PPDB and ECOTOX

-All the three representatvie scenarios in PRIMET considered for risk calculation
- PRIMET is used for risk assesment

-Seven randomly selected active ingredients (a.i.s) is processed for PRIMET risk determination

\section{Risk Assesemnt}

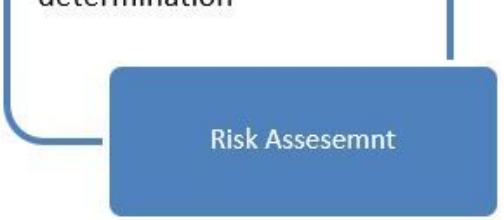

Figure 1

The process of risk determination
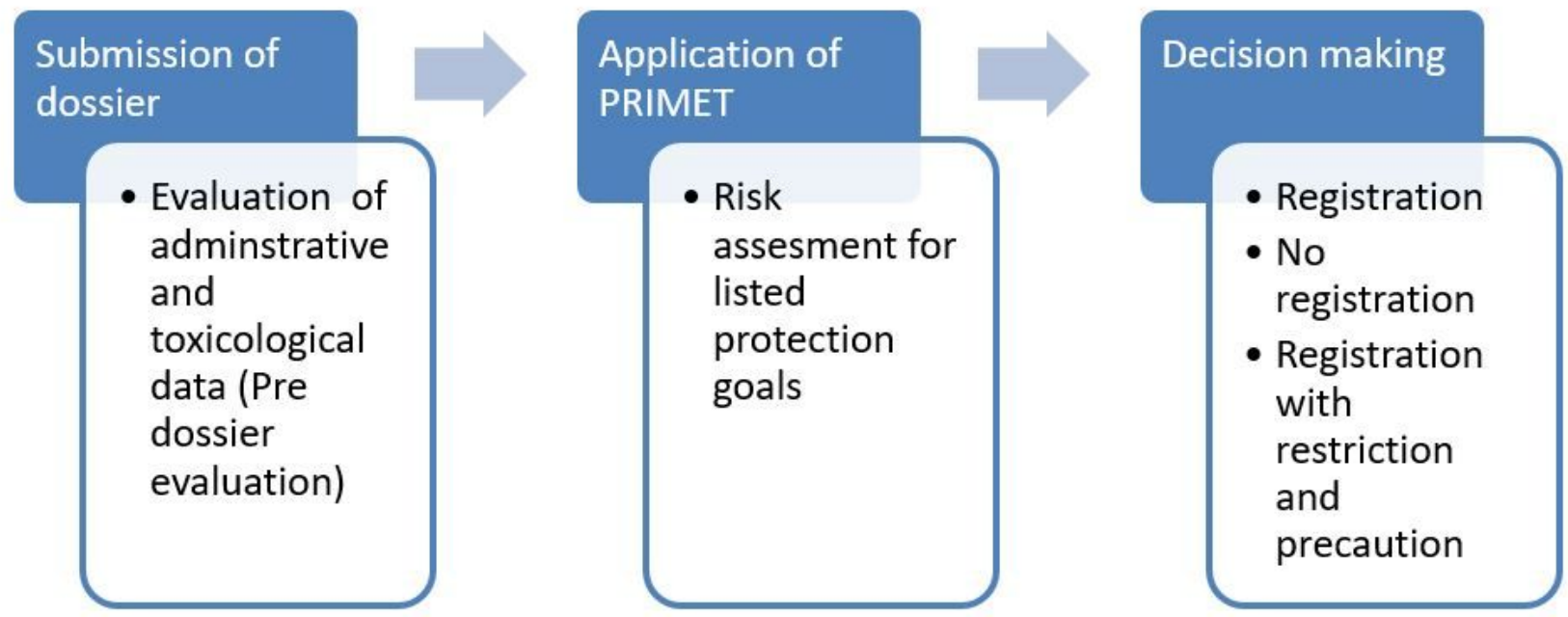

Figure 2

The decision-making process and the applicability of PRIMET

\section{Supplementary Files}

This is a list of supplementary files associated with this preprint. Click to download.

- Table5.jpg

- Table4.jpg

- supplimentarymaterials.xlsx 